\title{
Targeted supervised toothbrushing reduces caries increment
}

\author{
In children with high-risk of dental caries is supervised toothbrushing effective \\ in reducing disease?
}

\begin{abstract}
Curnow MMT, Pine CM, Burnside G, Nicholson JA, Chesters RKK Huntington E. A randomised controlled trial of the efficacy of supervised toothbrushing in High-Caries-Risk Children, Caries Res 2002; 36:294-300

Design Randomised Controlled Trial Intervention Supervised toothbrushing on schooldays with $1000 \mathrm{ppm}$ fluoride toothpaste with toothpaste and brushes supplied for home use one class in each school was allocated to intervention and compared to a within-school control over a 2-year period. Dental examinations were performed by a single-blinded examiner at 6 monthly intervals.
\end{abstract}

Outcome measure Visual examinations of caries at $D_{1}$ level (all visible cavitated and non-cavitated lesions in enamel and dentine). Approximal and occlusal surfaces were also examined using Fibre-optic transillumination (FOTI).

Results $86 \%$ of those examined at baseline completed study. At baseline children in both groups had similar levels of oral cleanliness; however, children from the more deprived areas had poorer levels of cleanliness. There was no significant difference between the groups in the caries increment in the deciduous teeth after 2 years. Dental immaturity had a significant effect on subsequent caries development. After 2 years there was a significantly less caries in the permanent molars in the intervention group, with $32 \%$ fewer $\mathrm{D}_{1}$ lesions $(95 \% \mathrm{Cl}$ $4-60 \%)$ and $56 \%$ fewer $\mathrm{D}_{3}$ lesions $(95 \% \mathrm{Cl} 13-101 \%)$.

Conclusions A targeted supervised toothbrushing programme with support for home use resulted in a significant reduction in caries increment.

\section{Commentary}

Although caries prevalence has declined in some populations it remains one of the most common childhood diseases in the world, particularly for those children of lower socio-economic status. ${ }^{1}$ High-level evidence exists for interventions such as community water fluoridation, fluoride toothpaste; fluoride mouth rinse, fluoride gel, fluoride varnish, and fluoride supplements to reduce caries prevalence. ${ }^{2}$ With several systematic reviews being conducted for a US National Institutes of Health Consensus Development Conference. ${ }^{3}$ While UK systematic review of water fluoridation discussed fluoridations beneficial effects over and above that offered by the use of alternative interventions and strategies, and the need for further clarification on the association between water fluoridation, caries and social class. ${ }^{4}$

This study looked at the reduction in 2-year caries increment that can be achieved by daily supervised tooth brushing. The authors were also interested in whether caries-preventive programmes previously provided for all schoolchildren could be reconsidered as a targeted population strategy.

Address for correspondence: Prof Cynthia Pine, Department of Clinical Dental Science, Liverpool University Dental Hospital and School of Dentistry, Pembroke Place, Liverpool, L3 5PS, UK. E-mail: cmpine@liverpool.ac.uk
This investigation and the published article are very well done; however, there are some minor deficiencies to consider. Although tooth brushing was supervised, there is no indication of the amounts of fluoride paste applied to the tooth brushes, or of the amounts expectorated into waste cups. There is no discussion of possible risks or side-effects with this fluoride tooth paste. Although it is assumed by the reader these children do not benefit from community water fluoridation, there is no clear statement of the amount of fluoride they potentially ingest in addition to the toothpaste. There is the risk of a "halo effect"; i.e., that tooth brushing - and therefore a reduction in caries incidence - might in fact improve in the control group simply because they are examined and because others nearby are known to be in a tooth brushing study. This would have the effect of underestimating the size of any benefit. The study is designed with the one variable, tooth brushing with fluoride tooth paste. It might be replicated with independent variables of tooth brushing, and tooth brushing with fluoride paste, against a control group to yield even more information.

At the end of this study, significantly less caries had developed in first permanent molars in the intervention group at both $D_{1}$ and $D_{3}$ levels. These benefits remained significant at the $\mathrm{D}_{3}$ level (and at the $\mathrm{D}_{1}$ level on clinical data only) when the data were stratified by dental immaturity; i.e., the number of first permanent molars erupted at baseline. To show a significant benefit to the deciduous dentition in such a high caries group, it is likely that the intervention would need to have occurred in the preschool years. Children with recently erupted or erupting teeth have the greatest potential to show a benefit with an effective caries-preventive agent. The data from this study support the conduct of a 1-year clinical trial on children selected on the basis of dental maturity rather than calendar age.

The authors state that these children will be further examined in the future to evaluate whether the reduction in caries increment and the habit of twice-daily brushing can be maintained without external intervention. This longer-term assessment will allow an analysis of costs and benefits. However, benefit of a supervised tooth brushing programme (with fluoride paste) in high-caries-risk children far outweighs the costs and potential side-effects.

Essentially, this study demonstrates that, in areas without the benefit of fluoridated water, the provision of toothbrushes and fluoride toothpaste to all children at risk could have a significant effect in reducing caries adding additional evidence to those conclusions published in the August 17, 2001 MMWR. $^{2}$

\section{Practice points}

- Targeted supervised toothbrushing with home support can produce significant reductions in caries levels.

- In order to prevent one carious surface at D3 level (cavitation into dentine) you would need to have two children in the supervised programme. 


\section{Richard D Bebermeyer}

Department of Restorative Dentistry and Biomaterials, The University of Texas Health Science Center at Houston - Dental Branch, Houston, TX 77030, USA
3. National Institutes of Health Consensus Development Conference. Diagnosis \& Management of Dental Caries throughout Life; program and abstracts. Bethesda MD: $2000 ; 115$

4. HS Centre for Reviews and Dissemination, University of York. A systematic review of public water fluoridation. 2000; ISBN 190064016 3:67.

1. Marthaler TM. Caries status in Europe and predictions of future trends. Caries Res 1990; 24:381-396.

2. MMWR - Morbidity and Mortality Weekly Report; Recommendations for using fluoride to prevent and control dental caries in the United States. 2001; 50 (No. RR-14):25.

Evidence-Based Dentistry (2003) 4, 49-50.

doi:10.1038/sj.ebd.6400193

\begin{tabular}{|c|c|c|c|c|c|c|c|}
\hline \multicolumn{8}{|c|}{$\begin{array}{l}\text { Key to evidence graphic used in Evidence-based Dentistry with examples of study } \\
\text { designs for Therapy/prevention/aetiology and harm. Study designs for evidence levels } \\
\text { will be different for prognosis/diagnosis etc. (See Evidence-based Dentistry } \\
\text { 2003;4:p17-18) }\end{array}$} \\
\hline & \multicolumn{2}{|c|}{ Evidence } & \multicolumn{3}{|c|}{ Graphic } & \multirow{2}{*}{$\begin{array}{c}\text { Evidence-level } \\
1 \mathrm{~A}\end{array}$} & \multirow{3}{*}{$\begin{array}{c}\begin{array}{c}\text { Therapy/Prevention } \\
\text { /Aetiology/Harm }\end{array} \\
\text { SR (with homogeneity }{ }^{\mathrm{a}} \text { ) of RCTs }\end{array}$} \\
\hline & & & & & & & \\
\hline $3 \mathrm{~A}$ & $2 C$ & $2 \mathrm{~B}$ & $2 A$ & 18 & $1 \mathrm{~A}$ & & \\
\hline & & & & & & $1 \mathrm{~B}$ & Individual RCT with narrow \\
\hline $3 A$ & $2 \mathrm{C}$ & $2 \mathrm{~B}$ & $2 A$ & 18 & $1 \mathrm{~A}$ & & \\
\hline & & & & & & $2 B$ & $\begin{array}{l}\text { SR (with homogeneity }{ }^{\mathrm{a}} \text { ) of } \\
\text { cohort studies }\end{array}$ \\
\hline $3 A$ & $2 \mathrm{C}$ & $2 \mathrm{~B}$ & $2 A$ & 但 & $1 \mathrm{~A}$ & & \\
\hline $3 A$ & $2 \mathrm{C}$ & $2 \mathrm{~B}$ & $2 \mathrm{~A}$ & 18 & $1 \mathrm{~A}$ & $2 \mathrm{C}$ & $\begin{array}{l}\text { Individual cohort studies } \\
\text { (including low quality RCT eg < }\end{array}$ \\
\hline $3 \mathrm{~A}$ & $2 \mathrm{C}$ & $2 \mathrm{~B}$ & $2 \mathrm{~A}$ & 18 & $1 \mathrm{~A}$ & $3 \mathrm{~A}$ & $\begin{array}{l}\text { SR (with homogeneity }{ }^{\mathrm{a}} \text { ) of Case- } \\
\text { Controlled Studies }\end{array}$ \\
\hline
\end{tabular}

By homogeneity we mean a systematic review free of worrisome variations (heterogeneity) in the direction and degree of results between individual studies. Not all systematic reviews with statistically significant heterogeneity need be worrisome, and not all worrisome heterogeneity need be statistically significant. 